\title{
Spawalnicze naprężenia i odkształcenia w konwencjonalnych ścianach szczelnych oraz ekranach nowej generacji
}

\section{Welding tensions and deformations in the conventional sealed walls and the new generation screens}

\section{Streszczenie}

W pracy przedstawiono porównanie symulowanych naprężeń i odkształceń spawalniczych powstających w płytach zaprojektowanych jako ściany szczelne. Wykazano, że spawanie ekranów spoinami pachwinowymi prowadzi do większych naprężeń i deformacji o $20 \div 35 \%$ niż spoinami czołowymi. Wskazano inne, liczne zalety innowacyjnego rozwiązania.

Słowa kluczowe: naprężenia spawalnicze; odkształcenia spawalnicze; ściana szczelna; spoiny pachwinowe i czołowe

\begin{abstract}
The paper presents a comparison of simulated welding tensions and deformations created in plates designed as sealed walls. It has been shown that welding of sealed wall elements with fillet welds leads to higher tensions and deformations by $25 \div 35 \%$ than in the case of butt welds. Indicated a number of other advantages of innovative solutions.
\end{abstract}

Keywords: welding tensions; welding deformations; sealed wall; fillet welds and butt welds

\section{Wstęp}

Jedną z podstawowych zasad projektowych i wykonawczych konstrukcji spawanych jest minimalizacja liczby i grubości spoin w nich występujących. Skutkiem spawania jest bowiem powstanie przestrzennego stanu naprężeń z powodu nierównomiernego nagrzewania łączonych elementów. Zatem doprowadzenie dowolnej ich części do temperatury wyższej od sąsiedniej, powoduje efekt odkształceniowy przeistaczający się w powstanie naprężeń. Jeżeli naprężenia te osiągną granicę plastyczności spajanych elementów, powstaje spęczenie (skrócenie) stref nagrzanych, co po ich ochłodzeniu skutkuje skurczem spawalniczym.

Skurcz ten może powodować pęknięcia stygnących spoin i powstanie wielokierunkowych odkształceń, zawsze jednak prowadzi on do powstania naprężeń pozostających - pozbawiających wyroby spawane części zapasu plastyczności, a zatem i podatności na odkształcenia. Efekty te są szczególnie niebezpieczne podczas i po spawaniu materiałów i konstrukcji o dużej sztywności (małym zapasie plastyczności), spowodowanej np. znaczną grubością elementów, przesztywnieniem konstrukcyjnym, naprężeniami odlewniczymi lub pochodzącymi od różnego typu obróbek technicznych.

Przykładem takich konstrukcji są ściany szczelne kotłów (rys. 1). Jeżeli są one wykonane z energetycznych stali nowej generacji, mogą sprawić wiele kłopotów spawalnikom

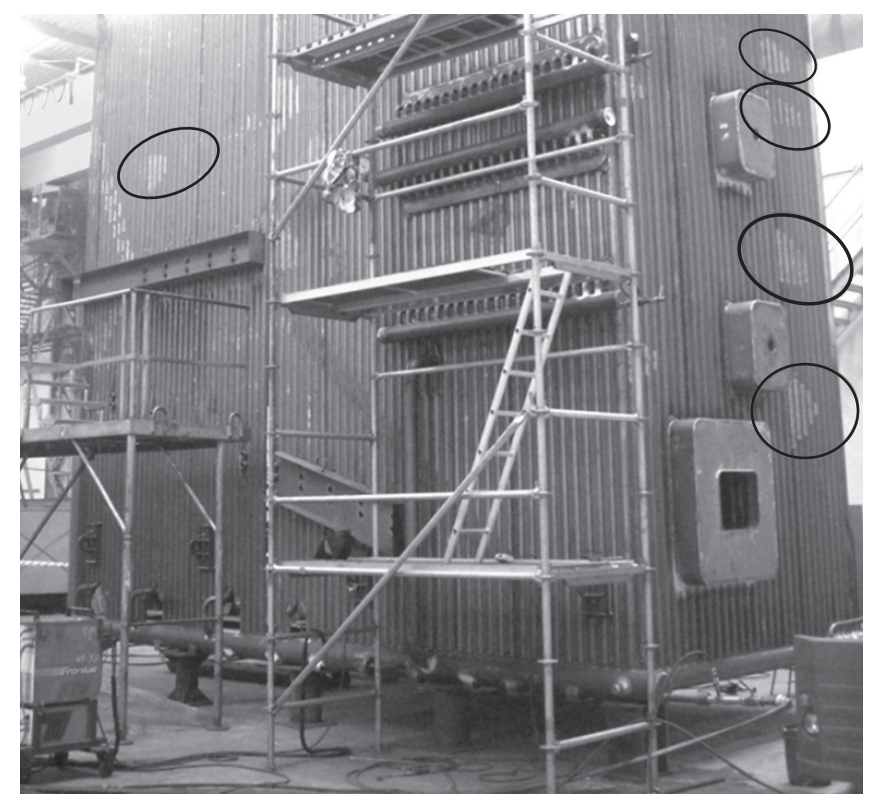

Rys. 1. Montaż kotła z widocznymi śladami po dwustronnym prostowaniu klinowym

Fig. 1. Boiler installation with visible traces on two-sided wedge straightening

Dr inż. Kwiryn Wojsyk, dr inż. Ryszard Krawczyk, inż. Daniel Wierzchowski - Politechnika Częstochowska.

Autor korespondencyjny/Corresponding author: kwiryn@gmail.com 
i energetykom [1,2]. Dowiodły tego próby wprowadzenia w Europie Zachodniej i Środkowej stali P/T24 do powszechnego użycia w latach $2010 \div 2012$ [3].

Kilkanaście wyłączeń bloków energetycznych miało złożone, w tym metalurgiczne przyczyny, jednak pęknięcia konstrukcji spawanych są zawsze wywoływane naprężeniami oddziałującymi na złącza. Ściany szczelne ze względu na swoją budowę rura-płaskownik-rura należą do konstrukcji o znacznej gęstości spoin. Tym pilniejsze staje się zbadanie konstrukcji, która wykonana jest z dwu- lub czterokrotnym zmniejszeniem liczby spoin.

Ekran tego typu można złożyć z rur z dwoma wypustkami po obu stronach pobocznicy, wykonanych np. metodą wyciskania [4]. Spoiny łączące rury wykonane będą w płaszczyźnie symetrii ekranu [5].

\section{Założenia eksperymentu symulacyjnego}

Eksperyment polegał na utworzeniu modeli płyt złożonych z rur spawanych czterema spoinami pachwinowymi (rys. 2a), do których przyłożono zewnętrzne siły ściskające, równoważne naprężeniom wywołanym przez spoiny, które będąc rozciągane powodują ściskanie płyt.

a)

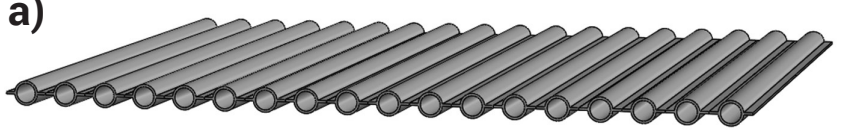

b)

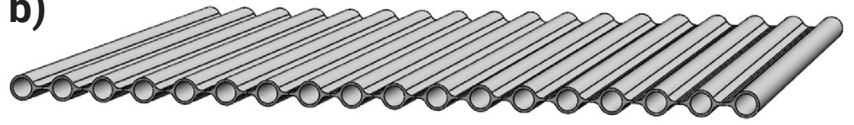

Rys. 2. Modele wykorzystywane w symulacji: a) płyta spawana czterema spoinami pachwinowymi; b) płyta spawana jedną spoiną czołową

Fig. 2. Models used in simulation: a) plate welded with four fillet welds; b) plate welded with one butt weld

Ponieważ ekran można wykonać składając rury lub całe segmenty różnymi sposobami, założono cztery rozkłady naprężeń odpowiadające możliwym wariantom zestawiania ekranów.

Założono, że płyty o wymiarach $1000 \times 1338 \mathrm{~mm}$ złożone są z 18 rur o średnicy $42 \mathrm{~mm}$ i grubości ścianki $4 \mathrm{~mm}$ rozstawionych z podziałką $72 \mathrm{~mm}$. Jako materiał przyjęto stal 1.4301 (X5 CrNi18-10) ze względu na przyszłe perspektywy jego zastosowania. Właściwości mechaniczne przyjętej stali zamieszczono w tablicy I.

Warianty odpowiadające różnym sposobom spawania ścian szczelnych wraz z otrzymanymi rezultatami przedstawiono w tablicy II.

Do wykonania obliczeń wykorzystano program Solidworks 2016 wraz z modułem Solidworks Simulation Premium, umożliwiającym przeprowadzenie analizy statycznej obciążonych płyt [6]. Ściany ekranowe obciążano tak, jak gdyby ekran był spawany symultanicznie (tabl. II/1), kolejne rury byłyby dospawywane (tabl. II/2), byłyby składane z trzech (tabl. II/3) lub dwóch segmentów (tabl. II/4) zespawanych wcześniej. Wybrane rezultaty symulacji przedstawiono na rysunkach $3 \div 6$.

Wynika z nich, że niezależnie od metody konstruowania ekranu w całość, naprężenia zredukowane $\mathrm{HMH}$, odkształcenia względne, jak i przemieszczenia są niższe o $20 \div 35 \%$ w przypadku spawania ekranu jedną spoiną czołową niż czterema spoinami pachwinowymi.

Ujemną cechą prezentowanego rozwiązania jest wyższy o $30 \div 50 \%$ koszt rur z wypustkami w stosunku do rur konwencjonalnych, jednak liczne zalety ekranów nowej konstrukcji przemawiają za ich wdrożeniem.

Podstawowe korzyści z zastosowania ekranów nowej generacji to:

- co najmniej dwukrotne (najczęściej czterokrotne) zmniejszenie liczby spoin i ich udziału w objętości konstrukcji ściany szczelnej;

- możliwość minimalizacji podziałki pomiędzy poszczególnymi rurami, co prowadzi do zwiększenia powierzchni czynnej ekranów;

- zmniejszenie poziomu wzdłużnych, poprzecznych i zredukowanych naprężeń spawalniczych;

- całkowite wyeliminowanie międzyoperacyjnego obracania elementów ekranów;

- eliminacja karbów kształtu wzdłuż spoiny i ścianek rur;

- skrócenie czasu i zmniejszenie kosztów spawania;

- zmniejszenie prawdopodobieństwa wystąpienia niezgodności spawalniczych ze względu na ograniczenie objętości spoin i wykorzystanie najkorzystniejszej, podolnej pozycji spawania;

- zastąpienie spoin pachwinowych czołowymi, co zwiększa trwałość i wytrzymałość konstrukcji rurowej;

- eliminacja spawania pozaosiowego powodująca zmniejszenie odkształceń spawalniczych;

- możliwość wykonania prostej obróbki mechanicznej i cieplnej spoin;

- ułatwienie i skrócenie czasu kontroli złączy, w tym zastosowania automatyki kontrolnej do regulacji i archiwizacji danych procesu spajania;

- możliwość kształtowania przejścia rura-wypustka metodami obróbki plastycznej;

- zastąpienie spawania w pozycji PB; najkorzystniejszym spawaniem w pozycji podobnej (PA), co przyspiesza spawanie;

- zmniejszenie liczby potencjalnych ognisk korozyjnych i miejsc wzmożonej turbulencji medium;

- zwiększenie zapasu plastyczności ekranu a przez to ułatwienie jego dalszego kształtowania plastycznego;

- zmniejszenie objętości, a zatem i masy ściany szczelnej;

- zmniejszenie zużycia materiałów dodatkowych do spawania;

- eliminowanie niebezpieczeństwa perforacji ścianek rur podczas spawania i zmniejszenie niebezpieczeństwa jej zaistnienia (atak wodorowy) podczas dalszej eksploatacji;

- poprawa możliwości skutecznego nanoszenia powłok chroniących wysokotemperaturową odporność erozyjnokorozyjną ekranów.

Tablica I. Właściwości mechaniczne stali X5 CrNi18-10 wg PN-EN 10088-1

Table I. Mechanical properties of X5CrNi18-10 steel according to PN-EN 10088-1

\begin{tabular}{|c|c|c|c|c|c|c|}
\hline \multicolumn{2}{|c|}{ Oznaczenie } & \multirow{2}{*}{$\mathbf{R}_{\mathbf{e}}, \mathrm{MPa}$} & \multirow{2}{*}{$\mathbf{R}_{\mathrm{m}}, \mathrm{MPa}$} & \multirow{2}{*}{$A_{5}, \%$} & \multirow{2}{*}{ Twardość, HB } & \multirow{2}{*}{ E, GPa } \\
\hline Znak stali & Numer stali & & & & & \\
\hline X5CrNi18-10 & 1.4301 & 400 & $500 \div 700$ & 45 & 215 & 200 \\
\hline
\end{tabular}


Tablica II. Warianty obciążeń płyt ekranowych i zestawienie wyników badań

Table II. Variants of screen plates load and a summary of the test results

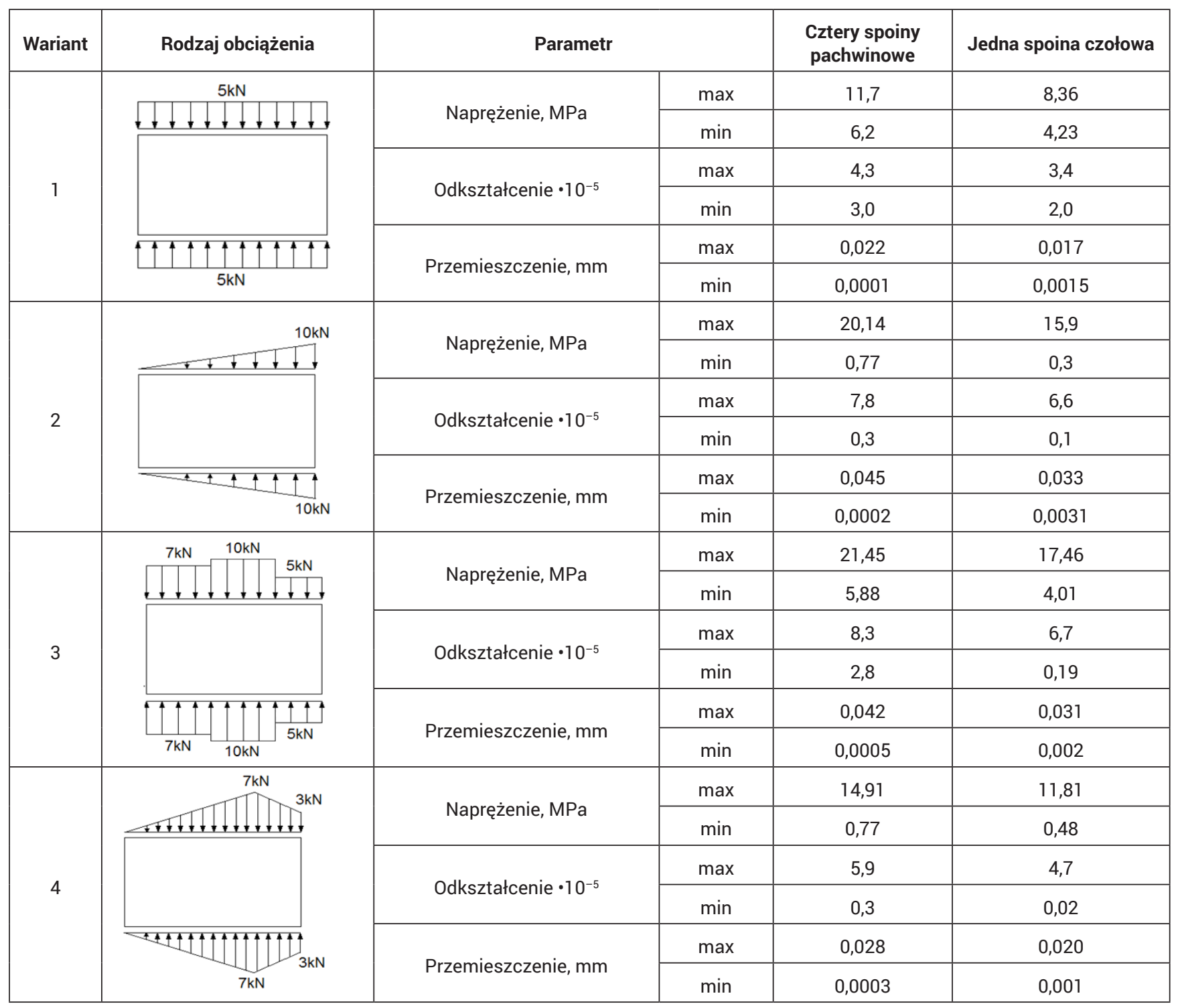

a)

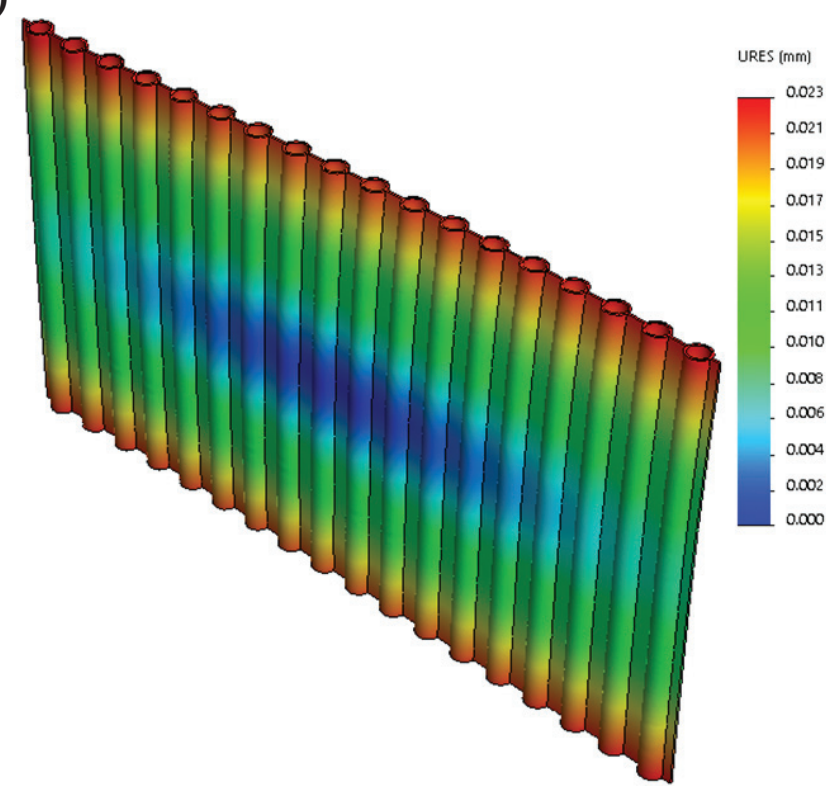

b)

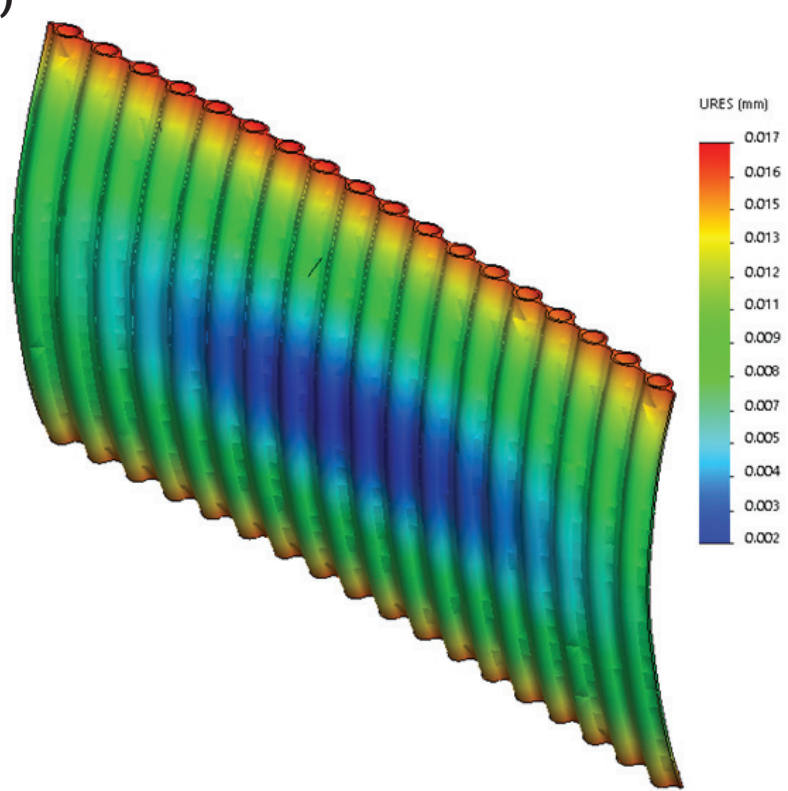

Rys. 3. Pole przemieszczenia ekranu przy ściskaniu płyty - wariant 1: a) ekran spawany czterema spoinami pachwinowymi, b) ekran spawany jedną spoiną czołową

Fig. 3. Displacement field of the screen during compression of the plates - variant 1: a) element welded with four fillet welds, b) element welded with one butt weld 
a)

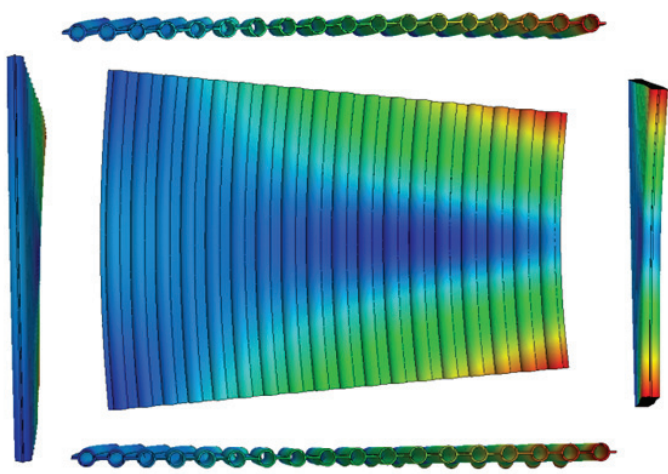

b)

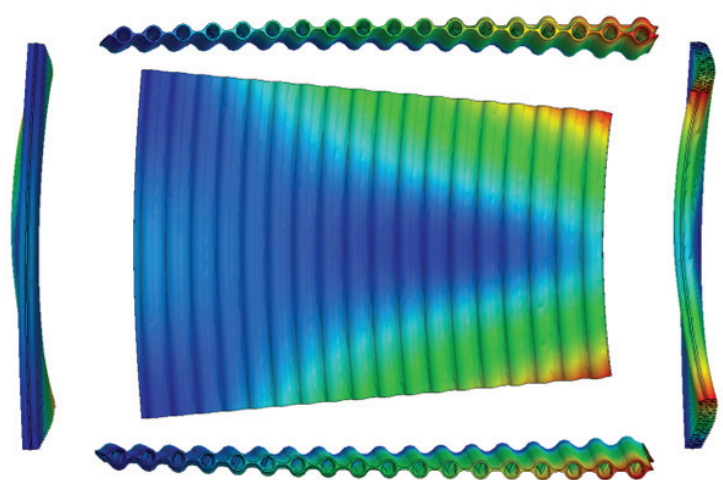

Rys. 4. Wyboczenie ekranu pokazane w różnych rzutach - wariant 2, wraz z polem przemieszczeń elementu przy zastosowaniu: a) spawania czterema spoinami pachwinowymi, b) spawania jedną spoiną czołową

Fig. 4. Screen buckling shown in different views - variant 2, together with the displacement field of the element using: a) welding with four fillet welds, b) welding with one butt weld

a)

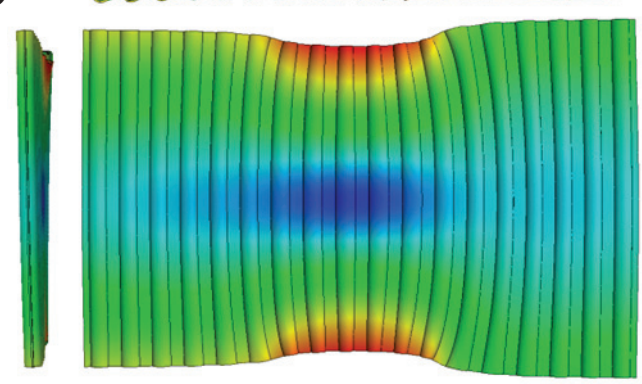

b)
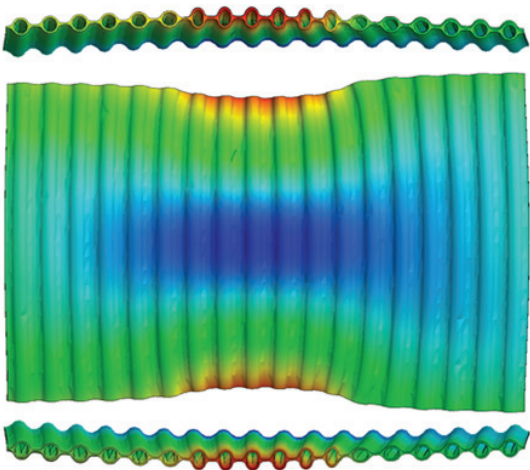

Rys. 5. Wyboczenie ukazane w różnych rzutach wariantu 3 spawania płyty wraz z polem przemieszczeń z zastosowaniem: a) czterech spoin pachwinowych, b) jednej spoiny czołowej

Fig. 5. Buckling shown in different views of variant 3 welding the plate together with the displacement field using: a) welding with four fillet welds, b) welding with one butt weld

a)

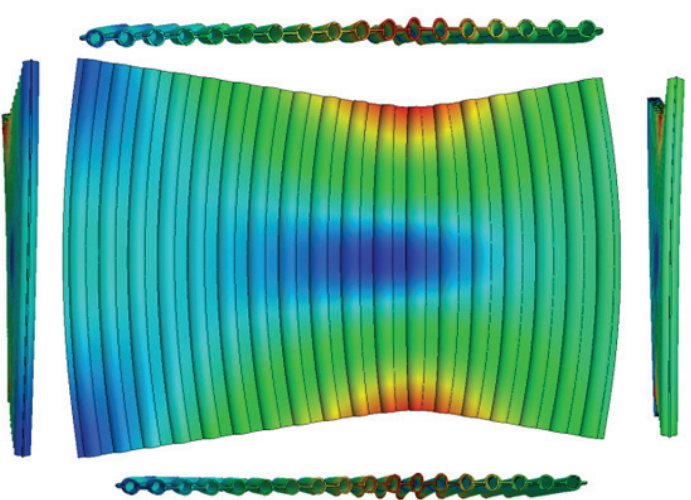

b)

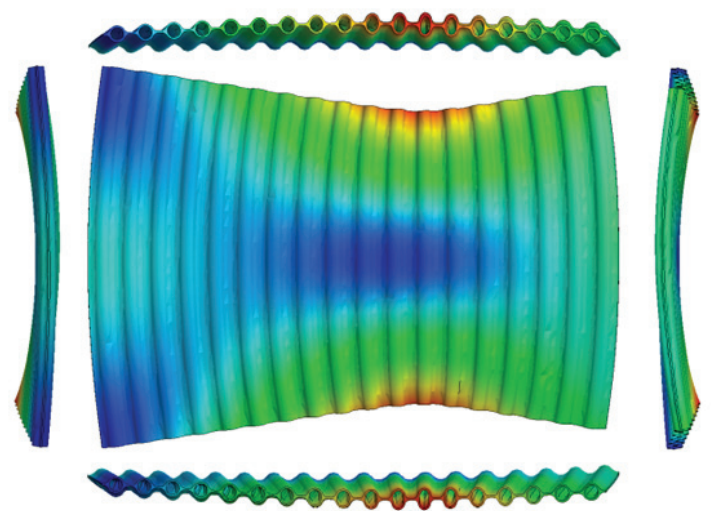

Rys. 6. Wyboczenie ukazane w różnych rzutach wariantu 4 spawania płyty wraz z polem przemieszczeń z zastosowaniem: a) czterech spoin pachwinowych, b) jednej spoiny czołowej

Fig. 6. Buckling shown in different views of variant 4 welding the plate together with the displacement field using: a) welding with four fillet welds, b) welding with one butt weld

\section{Podsumowanie}

Rozpatrywanie ekranów szczelnych o nowej konstrukcji jest perspektywiczne. Z konstrukcją ekranów o mniejszej liczbie spoin wiąże się szereg istotnych zalet produkcyjnych i eksploatacyjnych. Zmniejszenie naprężeń i odkształceń o $25 \div 30 \%$ może istotnie zwiększyć ich trwałość.

\section{Literatura}

[1] Brózda J.: Seminarium dotyczące stali dla nowoczesnych wysokowydajnych elektrowni i materiałów dodatkowych do ich spawania, Rudy Raciborskie 15.01.2009 r., Biuletyn Instytutu Spawalnictwa 2/2009, s. 12-15.

[2] Kudła K., Wojsyk K.: Possibilities of Constructing Sale and Cost-Effective Shields for Heat Exchangers, Polis Journal of Environmental Studies vol. 22, no. 6A, pp. 26-29, 2013

[3] Zasuń R.: Pech energetyka: kocioł pęka, woda sika, Gazeta Wyborcza 23.09.2011, s. 26.

[4] Michalczyk J., Wojsyk K.: Bezpieczne i ekonomiczne konstruowanie ekranów wymienników ciepła ze stali i innych stopów o ograniczonej spawalności, Przegląd Spawalnictwa 5/2014, s. 37-42.

[5] Kudła K., Wojsyk K.: Sposób wytwarzania ściany wymiennika ciepła, Patent RP nr 224 942, Warszawa 2017.02.02.

[6] Wierzchowski D.: Naprężenia i odkształcenia obliczeniowe w płytach wielokrotnie spawanych, Praca inżynierska, promotor dr inż. Kwiryn Wojsyk, Częstochowa 2016.- 